\title{
The Impact of Value on the Effectiveness of Marketing Communication of Local Companies
}

\author{
MÁria Demjanovičová \\ Department of Managerial Theories, Faculty of Management Sciences and Informatics, \\ University of Žilina
}

\begin{abstract}
Local companies from different areas that are successful in social networks were chosen for the survey. The aim of the article is to identify the companies' corporate values and their impact on the results of marketing communication as well as to find the attributes that are used in such successful companies and to make generalisation of them. Several local companies do not invest a lot of money in marketing, but their results in social networks are comparable or even better than the ones of corporations managed by social networking agencies. What is the essence of their success and how does it impact the value of the company? The paper describes the perceived value of entrepreneurs from small local companies through quality methods of research - personal interviews and the theoretical basis in this field. This data allowed for preparing research which shows four interest areas of the perceived value in small companies. The companies were selected from Slovakia, from among small and medium-sized companies in the local area in May 2019. In the research seventeen companies were involved and the main objective of the
\end{abstract}


research was to gain as much information as possible about the companies' value and the value perceived by the entrepreneurs. For this reason, personal interviews were used. The research results can bring parameters of the perceived value in the first step and later can provide a helpful model of managing value and the steps for understanding and creating the value of a local company.

Keywords: company, value, perceived value, product, marketing

JEL Classification Codes: M10, M31, M14

\section{Introduction}

An internal view of a given company on its value is the main trigger of its employees' motivation. When they identify with it, they mirror the success and achieve the company's goals. Linking its value to every section of the company is the most important factor for its really successful application.

If the value is only something like a paragraph of the articles of the company, part of the company's documentation and its content is known only by superiors and managers, in these conditions the value does not fulfil its task and it is only one word in the paragraph, without any other impact. But if the value of the company is part of its identity, too, it is part of thinking of everyone in the company and it is in connection with the product, with creation, production and with every output of the company. At present, value is really understood as part of the company's vision and mission, and it is beneficial for the achievement of the company's goals.

The research which is the base for this paper contains information from small companies in the local area - Žilina, Slovakia. It was performed on randomly selected companies from 3 different fields: the restaurant sector, services and production. The method of selection was of qualitative nature, it was performed through personal interviews, which provide more open information and give an overall view on the atmosphere and behaviour of the entrepreneurs. Thus, the output is more relevant.

The main objective was to find out what is perceived as value of the company by the entrepreneurs. It was also to provide an internal view of the company's value and to name the main parameters of it. In the next step, the parameters were compared with marketing communication in their social media - namely Facebook. The research focused on the correlation between these two rates, the perceived value (parameters of the perceived value) and the communication parameters in the social channel - Facebook. 


\section{Research questions}

1. What parameters are important for the local companies from the perspective of the perceived value?

2. Are companies more successful in the social channels when they communicate their internal value?

\section{Literature review}

Value can be understood as an internal spirit which is in every employee and in every activity connected to the company. It is something like an intrinsic drive of everything bearing the name of this company or acting in the name of this company. When the company is looking for value, they think about their own value, but in connection with their customers, and, last but not least, in connection with the environment, too.

Value focused on the customer is sometimes understood as value proposition. Michael Skok is a contributor in the Forbes magazine, he helps entrepreneurs to go from an idea to the real market. And his view on value proposition is that, in the simplest definition, it is a statement that explains what benefit you provide, for whom, and how you do it in the most unique way. This approach describes your target buyer, the problem which you solve, and why you are distinctly better than your rivals or other alternatives. When the company wants to set its specific value proposition, they have to consider these 4 steps (Skok, 2013):

- Define;

- Evaluate;

- Measure;

- Build.

Value can be viewed in many different ways. One of them is the perceived value. This metric is useful in companies as a key metric for understanding major values of the company (Chen, Lin, 2018). This point of view on value has various ways of description. For example, customer service preferences or purchase intentions can be determined by examining the perceived value. This finding can then be applied to create a key differentiation tool for maintaining a competitive advantage (Chen, Lin, 2018). The sense of the perceived value is based on the major value of a product or service that is perceived by clients/customers. It can be defined as the connection between the perceived benefits that are part of the product or service and the perceived cost that a customer has to pay (Lovelock, 2001) 
Social media marketing is the most important online communication tool which brings open possibilities for a company to be in all-day connection with their customers. The company can communicate everything, all the time. Certainly, this needs to be done with some schedule of publications planed with specific goals. Every campaign is different. Some of these activities are focused on increasing the reach of posts, some are focused on acquiring new followers. Everything depends on the company's preferences.

Kim and Ko (2012) studied the community marketing campaigns of luxury brands. They specified 5 major factors which can bring a significant impact on customers' brand equity, purchase intentions, etc. (Kim, Ko, 2012):

- Entertainment;

- Interaction;

- Trendiness;

- Customization;

- World-of-mouth.

Companies must build marketing activities according to different users' needs, they must understand their users' needs earlier than the users themselves do and learn which products users need in the next period (Kim and Perdue, 2013). The place that marketing activities hold in the hearts and minds of users has the most valuable impact on users' continued product use (Hsu and Tsou, 2011). The main condition of a good theory is based on generality (Griffin, 2003): a prepared model of the communication theory, which explains 3 basic properties - generality, accuracy, simplicity. In this time, it is important to understand what is needed of the customer. A typical error of decision-making is that marketing managers look for a market opportunity and they forget about customer needs, customer preferences, customer perceived value. Then companies produce products which are not interesting for their customers. The product is innovative and nice, but it does not meet the needs of the customer (Higham, 2009).

\section{Research information}

The survey for this paper is part of bigger research of small business models and communication models, it is about finding out how entrepreneurs perceive the value of their company, how they communicate it and how successful their marketing is.

The research sample for the first survey is from the local area - Slovakia, Žilina. The specifics of these companies are the number of employees - maximum 10. Every company has their own communication model, they do not use agencies or $3^{\text {rd }}$ party solutions. The companies are from 3 sectors: the restaurant sector (coffee shops, 
restaurants, etc.), production segment (furniture, toothbrushes, etc.) and services (wedding agency, laser arena, transport services, etc.). This research was conducted in May 2019. The companies in this research were selected based on the fact that the majority of micro and small companies are from these segments (restaurant, production, services).

Information about the companies was gained via qualitative methods - personal interviews with the head of a given company - entrepreneur. The outputs form these interviews are the specific parameters that explain the perceived value of each company from the perspective of its boss. From the results 4 main groups for the perceived value were created, consisting of 15 parameters, as shown in Table 1.

Here are the groups of the values perceived by the entrepreneurs:

- Product;

- Service;

- Environment;

- Emotions.

Table 1. Parameters of the value perceived by the entrepreneurs

\begin{tabular}{|l|l|}
\hline \multicolumn{1}{|c|}{ Area of perceived value } & \multicolumn{1}{|c|}{ Parameter } \\
\hline Product & $\begin{array}{l}\text { Quality } \\
\text { Bio } \\
\text { Local }\end{array}$ \\
\hline Service & Interior design \\
& Additional services \\
& Staff qualifications \\
& Custom access \\
& Special accessories \\
& Supplementary programme \\
\hline Environment & Waste recycling \\
\hline Emotions & Minimalisation of waste production \\
& Social business impact \\
& Eco products \\
& Atmosphere \\
Company name
\end{tabular}

Source: own elaboration.

Product is the most connecting output of a given company, which represents everything in connection with the customer. The specification of the product is very important these days, because customers are not interested in the price or the colour that much; they are interested in more specific factors and the companies understand this new perceived value of their products. For this reason, it is important to understand the main parameters of the perceived value, what it is, and why it 
is so important for them. The important parameters, such as quality, bio and local are at present likely to become marketing slogans. What does it mean in reality? Quality is a parameter of a product which is not only about the materials of the product and the process of producing it, but it is about the taste of it, about the style which this product represents, and much more. Bio and local are parameters that are in connection with the transparent communication. When a company communicates these two words, it is important to declare it by evidence, for example publish the list of suppliers with certificates of their production being bio, etc.

This type of communication is supported by services at a higher level. When the company wants to declare their local and bio suppliers it is good to communicate it in multiple ways. For example, on the website, in a blog article, or via printing leaflets in their company. Here is the next parameter that is important for entrepreneurs - interior design of the company, or the shop, or place which is in contact with the customers and it represents the company's brand. Customers want to be at a nice place and have the best services there. So, there is the next parameter - qualifications of the employees. And every customer wants to be the only one. They need to see that they are in the first place every time, they have the most specific order and the main focus of the company is to aim at them. Every of these parameters belongs to the basic package of services. Companies have to think about various interesting events and about more possibilities of connecting with their customers. The customers need to feel that they are part of the company and the company has to create possibilities for their relationships to grow.

This trend of community growing is a good strategy for the company. Because the company plans activities for internal teambuilding, and at the same time the company shows to the public that heir perceiving of the environment is at a high level, and they are interested in it. Companies recycle their waste, minimalise waste and propagate their positive social impact. At a higher level of their eco-friendliness, companies produce only eco-friendly products and they declare it.

Emotions are related to these activities. When companies are interested in their social impact, they think not only about earning money, but they want their identity to grow. Such companies are interesting not only for their customers, but for the employees, too. The employees identify with the company and they are proud of it. They are proud to be part of that. 


\section{Stakeholders}

The environment around a company affects every process and every output of it. For this reason, it is necessary to know and understand what is important for the company. It is also important to know what the main value for the company is as well as what is important for the communication with its customers.

The research brought information about the parameters that are important for the entrepreneurs and what they feel when thinking about value. Value is a really general word. For this reason, it is better to use the term perceived value. Then it is about what the entrepreneur feels to be the company's value. The parameters that were listed in Table 1 can be divided into more general groups, which can represent important interest areas of value, displayed in Figure 1.

Figure 1. Interest areas of the model for the perceived value in small companies

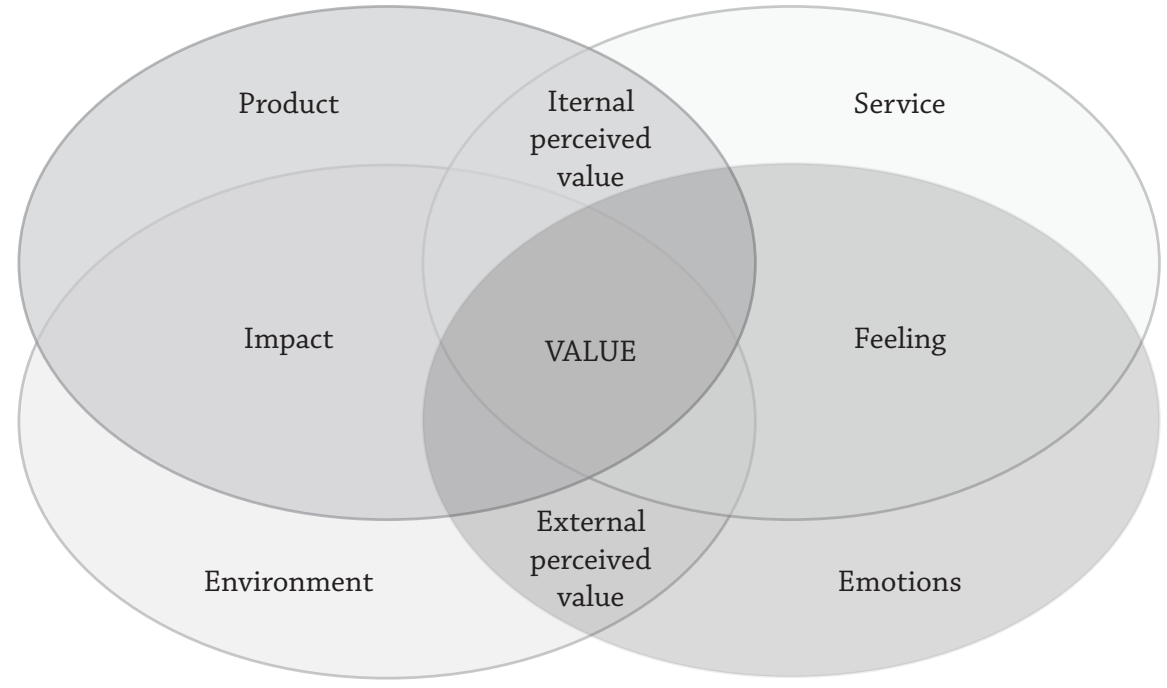

Source: own elaboration.

Four main areas which influence the perceived value are the product, service, environment and emotions, as shown in Figure 1. Two of these areas are from the internal conditions - from the company itself. The environment and emotions are from the external conditions. In this model, every part influences all other parts. The main parameter of this model is value. Value is the basis for everything. For the external conditions (environment, people, nature, etc.) and for the internal conditions, too (culture of the company, motivation, employees, success of the 
company, etc.). It is important to realise that the external perceived value (PV) affects only the external parameters. When a company is focused on the external perceived value, they satisfy the expectations of the customers, but the value of the company is not fulfilled. Companies in these situations forget about the employees, their goals, etc., such a company is only focused on the environment and its actual values. The opposite situation occurs with the internal perceived value (PV). It is when the company sees only its own value. They forget the second step of the successful fulfilment of the value. Because, when the company and their employees are interested in its value, they know it, they share it and they are motivated from it, but the value is established only in relation to the internal parameters. Thus, the company provides products and services which are not in connection with the customers' expectations. The impact on the environment is not important for such a company, and the contribution to the public is minimal. The future of such a type of the perceived value is only short-term. But when the company wants to know what their real value is, they need to know every aspect of it. To establish the value model and to make it functional, it is necessary to know every area, the internal as well as the external one.

\section{Conclusion}

The company is based on its value. Communication with its employees, with its customers, the corporate identity, every of these activities depends on its value. The first step for a successful value management is the knowledge of the internal perceived value and the external perceived value. The internal perceived value represents the knowledge of the entrepreneur, boss, or some other executive on what the company's value is. It is also about how important for the company these parameters of value are, and why the value is an important part of the company and its operations. The second part is to start detecting what is perceived as the value by the customer and the public. Why am I interested in this company as a customer? The company needs to start looking for preferences of the customer. What is our influence on the environment as a company? Where can I detect possibilities of creating emotions in the customers?

The research of this paper did not detect whether the perceived value parameters communicated in social media prove the success of the company. However, it detected that we need to know the importance of every parameter of value. When the research detects the strength of individual parameters, we can study how important every of the parameters is for the communication in social media. 
The paper defines the main general areas important for value detecting and the steps for managing value in the external as well as in the internal environment. The research will continue in detecting the perceived value of customers to acquire a more general view of value. Nevertheless, the early findings presented in this paper will create the necessary basis for the preparation of more general research with a higher number of companies involved. This way we can try to apply this model of detecting value and its effect on marketing communication in social media under the actual market conditions. This result can be helpful for companies in different fields. For example, services - restaurants, coffee shops, transport services, where it is important to build value, which can help create loyalty of customers. The environment needs to have our interest.

\section{Acknowledgement:}

This article is supported by the project VEGA: Diagnosis of specifics and determinants of strategic management of sports organisations, 2016-2019, 1/0617/16.

\section{References}

Griffin, E. (2003). A First Look at Communication Theory. London: McGraw-Hill, Inc. Higham, W. (2009). The next big thing. Great Britain: Kogan Page Limited. Hsu, H.Y., \& Tsou, H.T. (2011). Understanding customer experiences in online blog environments. International Journal of Information Management, 31(6), 510-523.

Kim, A.J., \& Ko, E. (2012). Do social media marketing activities enhance customer equity? An empirical study of luxury fashion brand. Journal of Business Research. ScienceDirect.com. 65(10), 1480-1486.

Kim, D., \& Perdue, R.R. (2013). The effects of cognitive, affective, and sensory attributes on hotel choice. International Journal of Hospitality Management, 35, 246-257.

Lovelock, C.H. (2001). Services Marketing, $4^{\text {th }}$ ed. Prentice Hall International. Retrieved from: https://www.academia.edu/8266372/Services_Marketing_PEOPLE_ TECHNOLOGY_STRATEGY_Sixth_Edition

Shih-Chih Chen, \& Chieh-Peng Lin (2018). Understanding the effect of social media marketing activities: The mediation of social identification, perceived value, and satisfaction. Science Direct, 140 (C), 22-32.

Skok, M. (2013, June 14). 4 Steps to Building A Compelling Value Proposition. Forbes. Retrieved from: https://www.forbes.com/sites/michaelskok/2013/06/14/4-stepsto-building-a-compelling-value-proposition/ 


\section{Mária Demjanovičová}

Currently working at the Faculty of Management Science and Informatics, focusing on the research in the field of value management and sustainability of small and medium-sized companies. After years of working in companies in the marketing department, she has found space for development of the perceived value within the whole business model not only in the marketing communication. For this reason, she looks for links between these perceptions from the perspective of entrepreneurs and customers.

e-mail address: demjanovicovaml@gmail.com 